\title{
Evaluation of toxicity of an organophosphate pesticide (Nogos) on behavior of the walking catfish (Clarias batrachus) and it's translocation in rice-fish ecosystem
}

\author{
S.A.A. SHIDDIQUE* AND M.A. MATIN ${ }^{1}$ \\ Department of Zoology, Dhaka University, Dhaka 1000, Bangladesh \\ ${ }^{1}$ Institute of Food and Radiation Biology (IFRB), BAEC, Savar, Dhaka, Bangladesh \\ *Corresponding Author: syedashraf4545@gmail.com
}

\begin{abstract}
The Present study investigated the toxic effects of the pesticide Nogos on the walking catfish Clarias batrachus, and its translocation and residual accumulation in a pesticide administrated rice-fish ecosystem under laboratory conditions. The experiment was conducted in aquaria containing soil collected from the paddy. Nogos was applied at five concentrations such as $0.085 \mathrm{ppm} .0 .170 \mathrm{ppm}, 0.255 \mathrm{ppm}, 0.340$ $\mathrm{ppm}, 0.510 \mathrm{ppm}$ and $0.595 \mathrm{ppm}$. A control was maintained without Nogos. An LC50 was obtained at a concentration of $0.31 \mathrm{ppm}$ Nogos. Nogos at a concentration of $0.595 \mathrm{ppm}$ showed $\mathrm{LC}_{100}$ to the fish while lower concentrations of $0.085 \mathrm{ppm}$ did not induce any mortality. Some behavioral changes noticed were: rapid opercular movement, jumping, jerking, erratic and circular movement, loss of equilibrium, leaching of mucous through anus, immobility and resting on the corners of the test aquarium, development of red spots on the dorsal surface, white spots on the abdomen. Maximum radioactivity was observed in water on day 2 $(1.1 \mu \mathrm{g} / \mathrm{g})$ of application of the pesticide. Soil sample showed peak radioactivity $0.55 \mu \mathrm{g} / \mathrm{g}$ on day 12 of application and thereafter declined slowly to background level by day 90 of pesticide application. Paddy root and shoot showed highest activity on day $24(0.24 \mu \mathrm{g} / \mathrm{g})$ and day $24(0.20 \mu \mathrm{g} / \mathrm{g})$, respectively.

Keywords: Clarias batrachus; Oryaza sativa, Nogos-100EC, Rice field, LC50
\end{abstract}

\section{Introduction}

Pests are troublesome or annoying or destructive animal, here, the insects, especially one that attacks food sources. The practice of intense mono cropping, have however brought the problem of pest attack of crops into sharp focus. It has been estimated that around 68,000 species of insects cause damage on man, domestic animals, plants and a wide variety of materials useful to man around the world (Melnikov 1971). During last 50 years, after introduction of synthetic organic pesticides, success, at least of a temporary nature could be claimed for the control of pests in agricultural fields. In Bangladesh, quite a large amount of pesticides are used in the agricultural fields. But due to lack of adequate knowledge, farmers broadened the pesticides over the crop fields in unscientific way. Recently, it was observed that water pollution resulting from industrial wastes and pesticide contamination of rivers, ponds, canals, soil etc. has exerted detrimental effects on the aquatic ecosystem (Rahman 1996, Mohammad et al. 2021). This may affect the aquatic animals, particularly the fish (Wang et al. 1996, Medina et al. 1991). Therefore the present study was designed to evaluate toxic effect of an organophosphorus, Nogos to Clarias batrachus and to trace its translocation, acute effects and chronic accumulation in rice plants and fish, in a simulated rice-fish ecosystem.

At present, scientific evaluation of toxic responses of synthetic chemicals has gained momentum in toxicity studies around the world. This is done by the determination of $\mathrm{LC}_{50}$ in topical application on terrestrial organisms and by determination of $\mathrm{LC}_{50}$ in aquatic organisms. It

https://doi.org/10.52168/bjf.2021.33.07 
is done by exposure of various doses through oral, dermal, ocular, inhalation. The most widely used test is the 96 hours $\mathrm{LC}_{50}$ value, as it is the most reproducible measure of toxicity. Tests for 24, 48 and 72 hours LC 50 values are also widely employed in toxicity studies. From beginning of the era of toxicity studies a good number of methods are followed for toxicity evaluation, however, the committee on methods for toxicity test with aquatic organisms (1975) listed only four techniques: (1) Static test wherein the test organisms are exposed the test solution once during the test; (2) Recalculations technique, which is almost, like static test except that the test solution is continuously circulated through an apparatus to maintain the quality of test solution constant and is returned to the test chamber; (3) Renewal technique, it is also almost like static test, only difference is test organisms are periodically exposed to fresh test solution of the same concentration usually once in every 24 hours; and (4) Continuous flow system in which the test solution passes through the test tank continuously at fixed flow rate, 3-6 or more liters per hour. Among the methods described above, the third method has been widely termed as static test, which has been used in the present experiment, as it is easy to practice in limited facilities. In Bangladesh, studies relating to toxicity of pesticides to fish are very meager, so far only a few reports are available (Sumon et al. 2018, Ali et al. 2018, Shahjahan et al. 2017, Akter et al. 2020, Habib et al. 2019). The objectives of the present study is to reveal the role of pesticidal activities of Nogos in agricultural crops and to assess the effects of Nogos on fish.

\section{Materials and Methods}

Test fish species: The experiment was conducted with the walking catfish (Magur) Clarias batrachus. C. batrachus of $15-20 \mathrm{~cm}$ in total length having a weight range of $45-55 \mathrm{~g}$ were used in this experiment. The average weight of the fishes was $50 \mathrm{~g}$ taken for the study. The fishes were acclimatized in dechlorinated tap water at room temperature $28 \pm 1^{\circ} \mathrm{C}$ for a period of one week before experimentation.

Test rice varieties: Rice variety Oryaza sativa (HYV), of one month old were transplanted in the aquarium, 50 hills, 3 plants/hill with a gap of about $4-6 \mathrm{~cm}$ in between sapling and the depth of water over the soil was $4 \mathrm{~cm}$ was maintained with frequent addition of pond water. The aquaria were placed in the rooftop, thus necessary light, temperature and other environmental conditions remained natural for the model ecosystem.

Selection of toxicant (Nogos/Dichlorvos) and test concentrations: Nogos (Dichlorvos) is an emulsifiable concentrated short-lived contact and stomach insecticide with fumigant action for the control of certain pests as indicated. Pilot experiments were conducted to fix the range of concentration. It was found that the range of concentrations which gave mortality in the range of $5 \%$ to $95 \%$ required to calculate the $\mathrm{LC}_{50}$ value. Since, in the aquatic environment an unknown dose of the toxicant cannot be applied directly to the test organisms, a known concentration of the toxicant in the medium that produces $50 \%$ kill is expressed as the $\mathrm{LC}_{50}$ values. In this case, $96 \mathrm{~h} \mathrm{LC} 50$ value of $C$. batrachus using Nogos as a pesticide in static test is given.

Study of translocation of Nogos: C- ${ }^{14}$ labelled Nogos (succinate. 2, 3-C ${ }^{14}$ labelled) with specific activity of $24.8 \mu \mathrm{c} / \mathrm{m}$ mol. supplied by IAEA, Vienna, was used. The radioactive isomers $\mathrm{C}^{14}$ Nogos was dissolved in n-hexane and added to the cold commercial formulation of Nogos (Fyfanon 57EC). This mixture had eventually $22.52 \mu \mathrm{ci}(0.3 \mathrm{mg})$ hot radioactive Nogos and 
$8.018 \mathrm{mg}$ cold Nogos (Fyfanon 57) and was mixed with ground paddy soil before spreading over the bottom of the glass tank. Nogos was allowed to incorporate into soil at a rate of 1-21 of active ingredient per hectare.

Design of the experiment: Twenty liters capacity glass aquaria were used as test containers. Ten fishes of approximately equal size were exposed to desired concentration of Nogos. The test water was changed every $4 \mathrm{~h}$. A stock solution of $1.666 \mathrm{mg}$ of Nogos per $\mathrm{ml}$ acetone was prepared. The stock solution was added to the test water. Equal volume of acetone was also added to the control tank as the volume of acetone was used in experimental tanks to prepare desired concentration of Nogos.

Collection of paddy samples for analysis: Three hill of paddy plants were randomly collected on day $1,2,3,6,12,18,30,42,54,78$ and at harvest time. The paddy plants were separated out into leaves, shoots and roots. The samples were cut and $100 \mathrm{~g}$ of each was homogenized with hexane: acetone mixture $(1: 1)$ to find out extract. The extract was then passed through anhydrous sodium sulphate and allowed to evaporate to dryness and the residues were finally taken up in $2 \mathrm{ml}$ of methanol. The residues were then used for radioactivity tests.

Toxicity test on fish collection of fish samples for analysis: The fishes were acclimatized for a period of 7-10 days in glass aquaria of 45 liter capacity in dechlorinated tap water. During acclimatization the fishes were given tubifex as food once in every $24 \mathrm{~h}$ and the water was changed within one hour of feeding. However, the fishes were not fed two days before exposing them to desired concentrations of pesticide. A batch of 10 experimental fishes were exposed to different concentrations of nogos with a mortality range from $\mathrm{LC}_{30}$ to $\mathrm{LC}_{80}$ and with concentrations of $0.166 \mathrm{ppm}, 0.243 \mathrm{ppm}, 0.332 \mathrm{ppm}, 0.415 \mathrm{ppm}, 0.498 \mathrm{ppm}$. Controls were also maintained along with experiments. In each concentration five experiments were conducted simultaneously and one control was maintained. So six glass aquaria were maintained simultaneously, five as treatments and one as control. The experiments were conducted for $96 \mathrm{~h}$. After 7 days of preparation, 25 C. batrachus with an average weight of $100 \mathrm{~g}$ were introduced in to that ecosystem. The mean mortality of five experiments was taken into consideration to determine the percentage mortality of each concentration. Fish samples were collected at random on $6,12,18,30,42,54,66,78$ and 90 days of exposure. The edible soft tissue (muscle) and visceral tissue of the fish were homogenized and combusted in the Harvex Biological Material Oxidizer. The $\mathrm{C}^{14}$ radio activity of the above mentioned samples prepared were measured by Liquid Scintillation Counter (Packard, Tricarb 1000).

Water analysis for hydrographic data: Water samples $(100 \mathrm{ml})$ were taken in triplicate randomly from each aquarium on day $1,2,3,5,6,12,18,24,30,42,54,66,78$ and 90 of exposure. Pesticide was extracted 3 times from water sample with chloroform in a separating funnel. The organic layers were pooled and passed through anhydrous sodium sulphate, evaporated to dryness. $\mathrm{C}^{14}$ Nogos residues in water were determined by direct Liquid Scintillation Counter (LSC), (Packard, Tricarb 1000). During acclimatization fishes were given tubifex as food once in every 24 hours. Within one hour of feeding, water of the acclimatization tank was changed with fresh water. When death of a particular batch of fish during acclimatization exceeded $5 \%$, it was discarded. Nitrate $\left(\mathrm{NO}_{3}\right)$ and phosphate $\left(\mathrm{PO}_{4}\right)$ were estimation using standard methods. 
EVALUATION OF TOXICITY OF AN ORGANOPHOSPHATE PESTICIDE ON BEHAVIOR OF C. BATRACHUS AND IT'S TRANSLOCATION IN RICE-FISH ECOSYSTEM

Soil Analysis: Individual soil samples were removed using remote handling device (Tongs) randomly on $1,2,3,5,6,12,18,24,30,42,54,66,78$ and 90 days of exposure. 20g soil sample was extracted with $250 \mathrm{ml}(1: 1)$ hexane: acetone solvent mixture in a soxhlet extraction flask for $24 \mathrm{~h}$. The extract was concentrated to almost dryness after drying over anhydrous sodium sulphate and residues were taken up in $2 \mathrm{ml}$ of methanol. $\mathrm{C}^{14}$ residues in soil were measured by LSC. A portion of the soil after extraction was combusted with oxygen in the Harvex Biological Material Oxidizer (Model ox-600).

\section{Results}

Behaviour of the experimental fish: At lethal concentration of $0.085 \mathrm{ppm}$ Nogos, the first sign of toxic effect of Nogos on test fishes was observed after $24 \mathrm{~h}$, beginning with rapid opercular movement and showed the sign of weakness. After $72 \mathrm{~h}$ a thread like mucous film started coming out of the anus. No mortality was observed in this concentration. At $0.170 \mathrm{ppm}$ Nogos the fishes started running fast. After $8 \mathrm{~h}$ started moving near the bottom of the aquaria. After 24 hours the test fishes stopped movement but with rapid opercula movement. The mucous thread was also seen coming out of the anus. A red spot was observed on the ventral side of the abdomen, the fishes started wondering on a zig-zag way. After $56 \mathrm{~h}$ of exposure the heads of the test fishes started surfacing. After $72 \mathrm{~h}$ the fishes downwards heads on the bottom of the aquaria. After $96 \mathrm{~h}$ mortality was observed and $30 \%$ fishes died in the concentration. At 0.255 ppm Nogos the exposed fishes ran fast. After $16 \mathrm{~h}$ the test fishes scales got detached from the skin. After $48 \mathrm{~h}$ a red spot developed on the trunk of three fishes on dorsal fin. After 56 and 72 $\mathrm{h}$ exposed first mortality and $40 \%$ fishes died within $96 \mathrm{~h}$. At $0.340 \mathrm{ppm}$ Nogos the test fishes showed mucous thread was seen coming out of the anus. After 60 and $68 \mathrm{~h}$ of exposure, some of test fishes became motionless, died and after $78 \mathrm{~h}$ a red spot developed gradually got enlarged between 92-96 h mortality rates was $54 \%$. In 0.510 ppm Nogos showed after 12, 40, 48 and 72 $\mathrm{h}$ the test fishes was seen white spot on the abdomen upwards. After $96 \mathrm{~h} 80 \%$ fishes died. At a higher concentration of $0.595 \mathrm{ppm}$ Nogos all the fishes died within $48 \mathrm{~h}$ of exposure.

Toxicity Study: The percent mortality of Walking catfish (C. batrachus) exposed to different levels of Nogos during a 7 day exposure period is given in Table I. No mortality was observed in fish exposed to $0.085 \mathrm{ppm}$ Nogos. But, in $0.170 \mathrm{ppm}$ of fish suffer $30 \%$ mortality and in $0.595 \mathrm{ppm}$ Nogos caused $100 \%$ mortality to fish kept both in sunlight or shade within 7 days of exposure. Fish exposed to $0.170,0.255,0.340$ and $0.510 \mathrm{ppm}$ of Nogos showed $30 \%-80 \%$ mortality within $0-5$ days of exposure. At higher concentration $(0.425,0.510$ and $0.595 \mathrm{ppm})$ the fishes exhibited sign of restlessness. Erratic swimming, convulsions and finally lost their balance. Toxicity studies using different concentration of Nogos for $96 \mathrm{~h}$ (exposure period shown $30 \%$ mortality in $0.170 \mathrm{ppm}, 40 \%$ mortality in $0.255 \mathrm{ppm}, 54 \%$ mortality in $0.340,69 \%$ mortality in $0.425 \mathrm{ppm}, 80 \%$ mortality $0.510 \mathrm{ppm}$ (Table I).

The $\mathrm{LC}_{50}$ value obtained by the above two methods were found to be very close to each other. So average value of the above two methods were taken as $\mathrm{LC}_{50}$ value which is $0.31 \mathrm{ppm}$. The $\mathrm{LC}_{50}$ value obtained in the present study is $0.31 \mathrm{ppm}$ at $28 \pm 1^{\circ} \mathrm{C}$. The $\mathrm{LC}_{50}$ value obtained in the present study indicates that Nogos is highly toxic to fish even at very low concentration. 


\section{S.A.A. SHIDDIQUE AND M.A. MATIN}

Table I. Mortality of $C$. batrachus in different concentrations of Nogos at $96 \mathrm{~h}$ of exposure

\begin{tabular}{c|c|c|c}
\hline Doses (ppm) & LC50 (log.conc.) & \% mortality & Probit mortality \\
\hline 0.085 & -1.081 & 0 & -- \\
\hline 0.170 & -0.769 & 30 & 4.48 \\
\hline 0.255 & -0.593 & 40 & 4.75 \\
\hline 0.340 & -0.468 & 54 & 5.10 \\
\hline 0.425 & -0.372 & 69 & 5.50 \\
\hline 0.510 & -0.292 & 80 & 5.84 \\
\hline 0.595 & -0.225 & 100 & 8.09 \\
\hline
\end{tabular}

Residues of Nogos in water: $\mathrm{C}^{14}$ Nogos added to the soil of the aquarium was found to disappear rapidly within the short period of time. $\mathrm{C}^{14}$ Nogos, residues in water monitored at different times are shown in Fig. 1, Maximum levels of residues occurred in water on the $1^{\text {st }}$ and $2^{\text {nd }}$ days were $0.85 \mu \mathrm{g} / \mathrm{g}$ and $1.1 \mu \mathrm{g} / \mathrm{g}$ respectively, of application of Nogos in the soil. These residues level decreased gradually with time and in 90 days its concentration comes down to about $0.05 \mu \mathrm{g} / \mathrm{g}$.



Fig. 1. Radioactivity in water from rice field expressed as Nogos.

Residues of Nogos in soil: The amount of radioactivity measured in soil of the paddy field is presented in Fig. 2. Nogos residues were found to bound in the soil as early as $0 \mathrm{hr}$. after addition the pesticide and tended to increase to a maximum Nogos equivalents of $0.55 \mu \mathrm{g} / \mathrm{g}$ on day 12 (Fig. 2). Whereas, 6 days after Nogos application, soil showed a concentration 0.48 $\mu \mathrm{g} / \mathrm{g}$. The level gradually decreased as the day passed by and at 90 days its concentration came down to $0.10 \mu \mathrm{g} / \mathrm{g}$.



Fig. 2. $\mathrm{C}^{14}$-residue in the soil of the rice field expressed as Nogos. 
Residues of Nogos in rice plant: The residue levels of $\mathrm{C}^{14}$ measured at different times is represented in Fig. 3. On the $1^{\text {st }}$ day, root contained $0.01 \mu \mathrm{g} / \mathrm{g}$ residue and it increased up to the peak at $0.22 \mu \mathrm{g} / \mathrm{g}$ on $24^{\text {th }}$ day. Then the concentration gradually downgrades and at 90 days it came down to $0.03 \mu \mathrm{g} / \mathrm{g}$. In shoot of the rice plants, the level of residue was negligible as compared to roots of the rice plants. Appreciable amount of residue was estimated on the $1^{\text {st }}$ and $2^{\text {nd }}$ days, while in the $3^{\text {rd }}$ day it rose up to $0.05 \mu \mathrm{g} / \mathrm{g}$. Maximum levels of residues were detected in plants shoot $(0.22 \mu \mathrm{g} / \mathrm{g})$ on the $24^{\text {th }}$ day after application of the pesticide. There was no residue in the shoot of rice plant on $90^{\text {th }}$ day onward i.e., at the time of harvest.

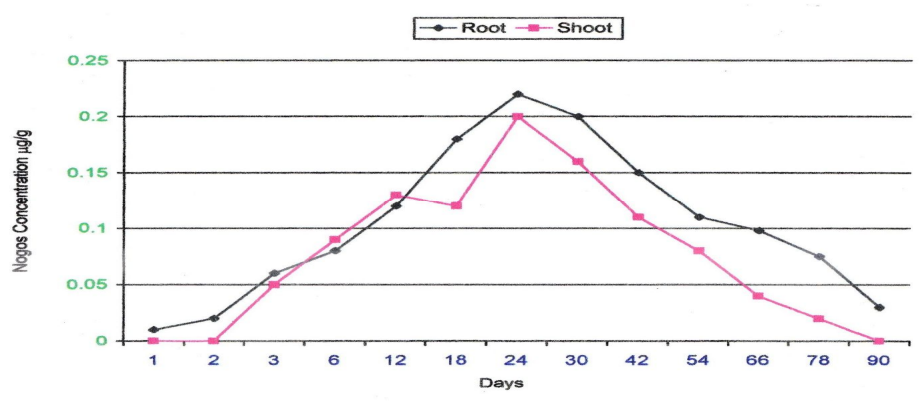

Fig. 3. C14-radioactivity in shoot and root systems of rice plant.

\section{Discussion}

The organophosphate pesticide (Nogos) is being widely used in the agricultural lands of Bangladesh to cut down the effect of various pests in rice and other fields. These pesticides have severe effect on the human health, as these are biocides. But to make clear understanding on how these pesticides translocate in the plants and other animals from the soils have demand of time. Keeping this view in mind, the present experiment has been initiated. For the study, rice plants were taken as the representative of plant kingdom, as these pesticides are widely used in the paddy fields in Bangladesh. The test fish taken, is the Walking catfish, C. batrachus, because this is a hardy fish and it has wide acceptance both in rural and urban areas.

During this study, it was seen that, exposed to different concentration and different time of exposure in Nogos $C$. batrachus showed abnormal behavior, such as erratic swimming movement, increased opercular activity, jumping out of the test media, jerking, first erratic and circular movement, loss of equilibrium, are quite similar to those observed in fishes treated with various pesticides (Rao et al. 1967, Verma et al. 1977, Sultana et al 2021). Determinations of $\mathrm{LC}_{50}$ Value of a chemical toxicant for aquatic organisms is one of the most widely accepted method of toxicity study where in toxicity is assessed by the concentration of toxic compound in water that kills half of the animals exposed for a specific period of time. In the present study percent mortality in different concentrations of Nogos showed a strait time, when log concentrations of Nogos was plotted against probit mortality a sigmoid curve was obtained respectively. Thus agreeing with the probit analysis (Finney 1964).

Excess mucous secretion observed in the present study has earlier been reported in a fish exposed to phenol (Mitrovic et al. 1968). Excessive mucous secretion may be a protective device to prevent absorption of toxicant by way of binding it with mucous, which is expelled out 
of the body through the anus in the form of mucous thread. Konar (1969) reported LC50 value of Nogos for Khalisa (Trichogaster fasciatus) 1.82ppm,for Channa punctatus $0.76 \mathrm{ppm}$, for Macrognathus aculeatus $3.55 \mathrm{ppm}$, for Nandus nandus $2.60 \mathrm{ppm}$, for Rita rita $2.75 \mathrm{ppm}$, for singhi (Heteropneustes fossilis) $17.78 \mathrm{ppm}$. The LC $\mathrm{L}_{50}$ value obtained in the present study is 0.31 ppm at $28 \pm 10 \mathrm{C}$. The low $\mathrm{LC}_{50}$ value may be due to the smaller size of fish and also due to species difference, The $\mathrm{LC}_{50}$ value obtained in the present study indicates that nogos in highly toxic to fish even at low concentration .

The percent mortality of Walking catfish (C. batrachus ) exposed to different measured levels of Nogos during a 7 days exposure period is given in Table I. While no mortality was observed in fish exposed to $0.085 \mathrm{ppm}$ Nogos. But $0.595 \mathrm{ppm}$ Nogos caused $100 \%$ mortality to fish. However fish exposed to $0.170,0.255,0.340,0.425$ and $0.510 \mathrm{ppm}$ showed $30 \%-80 \%$ mortality. The behavior of fish was also affected by Nogos exposure. The fishes at higher concentrations $(0.425,0.510$ and $0.595 \mathrm{ppm})$ exhibited sign of restlessness, erratic, swimming, convulsions and finally lost their balance, dashed against the wall of the glass tank and sank to the bottom before death. Ferrando et al. (1991) also reported the same result. Residues of Nogos in water was found decreased slowly with time because of translocation of pesticide to the other components such as fish, plants and soil with increase of the time. Therefore, the concentration gradually decreased up to its minimum at the end of experiment. Sun et al. (1989) also came with some findings.

Residues of Nogos in soil also decreased with time as these are translocate to various parts of the plant body and various organs of the fish and other animals. Sun et. al., (1989) also came with same conclusion. Jebakumar (1982) reported that soil showed slow release of the compound and after 14 days the residue levels decreased in case of $\mathrm{C}^{14}$ monocrotophos. But in case of Nogos, very little work was done in rice fish ecosystem. The residue levels of Nogos in rice plant measured at different times is represented in Fig. 3. No residues of Nogos has been found at the time of harvesting, i.e., 90 days onwards. This might be due to the dissociation of Nogos residues.

Translocation of an organophosphate pesticide (Nogos) has been evaluated using rice plant as test plant and Walking catfish ( $C$. batrachus) as test animal. The tests have been done on 1, 2, $3,4,5,6,12,18,24,30,42,54,66,78$ and 90 days intervals. Formation of mucous layer around the body of the test fish observed in the present study. The $\mathrm{LC}_{50}$ value obtained in the present study is $0.31 \mathrm{ppm}$ at $28 \pm 1.0 \mathrm{C}$. The LC 50 value obtained in the present study indicates that Nogos is highly toxic to fish even at very low concentration. No mortality was observed in fish exposed to $0.085 \mathrm{ppm}$ Nogos. But, $0.595 \mathrm{ppm}$ Nogos caused $100 \%$ mortality to fish. However, fish exposed to $0.170,0.255,0.340,0.425$ and $0.510 \mathrm{ppm}$ showed $30 \%-80 \%$ mortality. The pesticides has been found to be translocated as and when these are administrated into the soil, however, disappeared with time. The pesticide has also shown to appear in the plant at the time of administration and rose to a certain stage and then gradually disappeared. The behavior of fish was also affected by Nogos exposure. 


\section{EVALUATION OF TOXICITY OF AN ORGANOPHOSPHATE PESTICIDE ON BEHAVIOR OF C. BATRACHUS AND IT'S TRANSLOCATION IN RICE-FISH ECOSYSTEM}

\section{Literature Cited}

Akter, R., A.M. Pervin, H. Jahan, S.F. Rakhi, A.H.M.M. Reza and Z. Hossain, 2020. Toxic effects of an organophosphate pesticide, envoy $50 \mathrm{SC}$ on the brain acetyIcholinesterase activities in staining catfish (Heteropneustes fossilis). J. Basic Appl. Zool., 81: 47. https://doi.org/10.1186/s41936-02000184-w

Ali, M.H., K.A. Sumon, M.A. Sultana and H. Rashid, 2018. Toxicity of cypermethrin on the embryo and larvae of gangetic mystus, Mystus cavasius. Environ. Sci. Pollut. Res., 25: 31-99.

Ferrando, M.D., E. Sancho and E. Andrewmoliner, 1991. Comparative acute toxicities of selected pesticides to Anguilla anguilla. J. Environ. Sci. Health., B26 (5\&6 ): 491-498.

Finney, D.J., 1964. Probit analysis $2^{\text {nd }}$ ed. Cambridge, University Press, 20p.

Habib, M.A., M.J. Islam, S.K. Pramanik and M.C. Devsharmma, 2019. Effect of different levels of organocarbamate insecticide ( Sevin 85 SP ) on four local fish species of northern Bangladesh. South Asian J. Biol. Res., 2(2): 49-57.

Jebakumar, S.R.D., 1982. Effect of chosen pesticide on the paddy field ecosystem studies using model system, PhD Thesis, Maduri Kamaraj University, Maduri, India.

Konar, S.K., 1969. Histopathological effects of the insecticides, hepatachlor and nicotine, on the gill of the catfish, Heteropneustes fossilis. Jap. J. Ichthyol., 15(4): 156-159.

Medina, M.J.B., 1991. Persistance, absorption \& movement of Chloropyriphos in a paddy soil. MS dissertation. College of Agriculture, J. Econ. Entomol., 83(1): 226-233.

Melnikov, N.N., 1971. Chemistry of pesticides: Derivatives of the ditheocarbamic acids. Residue Rev., 36: $480 p$.

Mitrovic, V.V., V. Brown, D.G. Shurben and M.H. Berryman, 1968. Some pathological effect of subacute and acute poisoning of rainbow trout by phenol in hard water. Wat. Res., 2: 255-26.

Mohammad, A.H.B., H.M. Rahman, A.M.Z. Uddin, M.A. Rahman, B.S. Bidyut and I.S.M. Didar, 2021. Contamination of pond and canal water by residues of organophosphorus and carbamate pesticides in Feni district, Bangladesh. Environ. Sustain., 4: 191-197.

Rahman, M., 1996. Fate and distribution of $\mathrm{C}^{14}$-Chloropyriphos in rice-fish ecosystem. MS.

Rao, T., S.D. Shivaji and K. Magiah, 1967. Tim values of some modern pesticides to freshwater fish. Environ. Health. 9: 103-109.

Sun, J., I. Gon and Z. Chen, 1989. Fate of carbofuran in model rice fish ecosystem. Pesti. Sci., 26: 147187.

Sumon, K.A., H. Rashid, E.T.H.M. Peeters, R.H. Bosma and P.J. Banden Brink, 2018. Environmental monitoring and risk assessment of organophosphate pesticides in aquatic ecosystem of north-west Bangladesh. Chemosphere, 206: 92-100.

Shahjahan, M., M.F. Kobir, K.A. Sumon, L.R. Bhomik and H. Rashid, 2017. Toxicity of organoposphorous pesticide sumithion all larval stages of sting catfish Heteropneustes fossilis. Chinese J. Oceanol. Limnol., 35: 109-114.

Sultana, S., M. Nasiruddin and M. Chowdhury, 2021. Toxicalogical effect and behavioral response of a predatory Stinging Catfish, Heteropneustes fossils exposed to three indigenous plant seed extracts. Bangladesh. J. Zool., 48(2): 379-391.

Verma, S.R., S.K. Bansal and R.C. Dalela, 1977. Quantitative estimation of bio ide residues in a few tissues of Labeo rohita and Saccobnanchus fossilis. Indian J. Environ. Health, 19(2): 107-115.

Wang, H., Z. Zhang, G. Ren, D. Guo, S. Wu and Z. Cheng, 1996. Residues of C14 compl Monocrotophos in rice ecosystem. IAEA, Technical report, Vienna. 